\title{
Model and application of renewable energy accommodation capacity calculation considering utilization level of inter- provincial tie-line
}

\author{
Guodong Li, Gengyin Li ${ }^{*}$ and Ming Zhou
}

\begin{abstract}
At present, the problem of abandoning wind and PV power in "Three North" region of China is particularly significant, and how to alleviate this problem has become the focus of universal attention. Calculation of renewable energy accommodation capacity is the basis to solve the problem of abandoning wind and PV power. Main problems of Chinese renewable energy accommodation is analyzed from power supply, power grid and load side aspects, and it focuses on the effect of inter-provincial tie-line to renewable energy accommodation capacity. At present, the interprovincial tie-line utilization level is limited, which affected renewable energy accommodation to a certain extent. Based on the sequential production simulation model, a new kind of renewable energy accommodation capacity model is put forward considering the utilization level of inter-provincial tie-line. According to different system stability constraints and different electricity constraints of inter-provincial tie-line, 4 schemes are designed for comparative analysis, and the evaluation model is used to calculate renewable energy accommodation capacity of "Three North" region of China in 2020. Example analysis results verify validity of the model that releasing curve constraints, electricity constraints and stability constraints in turn can significantly enhance renewable energy accommodation capacity through effective use of inter-provincial tie-line transmission capacity. Research work in this paper can provide strong support for the planning and scheduling control of power grid.
\end{abstract}

Keywords: Renewable energy accommodation capacity, Sequential production simulation, Inter-provincial tie-line, Stability constraints

\section{Introduction}

By the end of 2017, installed capacity of China's power generation has exceeded 1.77 billion kilowatts. Among them, non-fossil energy accounts for more than $38 \%$ of installed capacity. Wind power and solar power both rank first in the world [1]. The sustained and large-scale development of renewable energy has brought about green energy, promoted energy conservation and emission reduction. On the other hand, it has also given power grid enormous pressure on renewable energy accommodation. In recent years, the problem of wind abandonment and PV abandonment in China has become increasingly prominent. In 2016, the

\footnotetext{
* Correspondence: ligy@ncepu.edu.cn

Key Laboratory of Alternate Electrical Power System with Renewable Energy Sources, North China Electric Power University, Changping District, Beijing
} 102206, People's Republic of China

\section{Springer Open}

(c) The Author(s). 2019 Open Access This article is distributed under the terms of the Creative Commons Attribution 4.0 International License (http://creativecommons.org/licenses/by/4.0/), which permits unrestricted use, distribution, and reproduction in any medium, provided you give appropriate credit to the original author(s) and the source, provide a link to the Creative Commons license, and indicate if changes were made. exceeded 40 billion $\mathrm{kWh}$ [2]. In 2017, the amount decreased slightly, but still very high. In order to accurately and efficiently calculate renewable energy accommodation capacity of grid, it is of great practical significance to carry out capacity calculation of grid to absorb renewable energy, and has wide application value in many aspects, such as power grid planning [3], dispatching operation $[4,5]$ and market transaction [6].

At present, there are a lot of researches on the calculation and evaluation methods of renewable energy accommodation capacity based on time series production simulation in relevant References. Reference [7] puts forward evaluation method of renewable energy accommodation capacity based on time series production simulation from annual time level, establishes mixed integer 
programming model, and develops relevant simulation software on this basis. The accuracy of this method is verified by relevant simulation software by CEPRI. Reference [8] also studies and establishes a simulation model of sequential production including wind and PV generation from annual time level. The model is solved by branch-and-bound method, which takes into account characteristics of renewable energy output, load and heating units, and has certain practical value. In reference [9], objective function of wind power accommodation assessment is modeled by wind power accommodation interval, and the upper and lower bounds of wind power accommodation are given considering stability constraints, unit output constraints and wind power output prediction in complex power network. Time series production simulation methods always are applied to annual accommodation capacity assessment of provincial power grid, which mainly corresponds to long-term application of power grid planning, and the application of power grid operation angle is relatively limited.

The above methods are all long-term evaluation methods. In order to achieve more precise calculation of accommodation capacity, it is necessary to evaluate system network constraints, unit commitment constraints, economy and other issues from day-ahead and intraday perspective. In reference [10], based on production simulation method of unit commitment, cost composition of wind power accommodation in power grid is analyzed from the cost point of view. It is deduced that wind power accommodation is related to system operation mode, unit parameters and other factors. References [11, 12] study day-ahead assessment model of renewable energy accommodation capacity considering SCED model. This method is helpful to improve effectiveness and practicability of power grid dispatch planning. References $[13,14]$ carry out real-time assessment of wind power accommodation capacity considering node voltage and line power flow constraints. The real-time wind power accommodation capacity assessment method considering network security constraints and wind-fire-water multi-objective coordinated optimal dispatching model is proposed. References $[15,16]$ study stochastic unit commitment problem considering wind power accommodation and peak load regulation, and discuss unit commitment with large-scale wind power connected to grid. The assessment of renewable energy accommodation capacity on day-ahead and intraday time scale further enriches the assessment connotation, but relevant methods basically concentrate on provincial power grid, and do not fully consider the utilization level of inter-provincial and inter-regional tie-lines.

On the other hand, most of existing calculation methods of renewable energy accommodation capacity are carried out at theory level, and few applied researches are aimed at actual grid operation. Reference [17] studies and analyzes assessment model of wind power accommodation capacity of inter-regional power grid, and puts forward relevant measures to improve accommodation capacity. Reference [18] carries out assessment of wind power accommodation capacity in combination with grid influencing factors and wind power's self-factors, and carries out application verification in Beijing-Tianjin-Tangshan power grid, and also puts forward countermeasures to maximize accommodation capacity of wind power. Reference [19], in view of situation of large-scale renewable energy accommodation in China, a renewable energy regional interconnection accommodation capacity analysis model is put forward, and comparison and analysis are made according to different DC adjustment operation modes. The economic and social benefits of the transmission curve with renewable energy output characteristics of DC tie-line are verified by examples.

With existing calculation methods of renewable energy accommodation capacity for large power grid, it is difficult to effectively support actual grid planning and operation control. Aiming at the practical engineering problem of abandoning wind and PV in the "three north" area of China, this paper presents a new calculation model of renewable energy accommodation capacity on the basis of time series production simulation model. The proposed model takes into account utilization level of inter-provincial and inter-regional tie-lines, making calculation results more in line with actual project needs and can solve China's problems. The practical problem of calculating accommodation capacity of renewable energy in "three north" area has certain guiding significance for grid planning and actual regulation and operation.

\section{Analysis of practical engineering problems}

Figure 1 shows renewable energy accommodation space. The minimum technical output of system is the fundamental restriction on renewable energy accommodation capacity. The total of load with tie-line power (equivalent load) in this region minus minimum technical output (Min-TO) is system accommodation capacity. As can be seen from Fig. 1, besides influence of renewable energy output, renewable energy accommodation capacity is mainly affected by minimum technical output (power supply side), tie-line outgoing power (power grid side) and system load (load side).

\subsection{Power side analysis}

The influence of power side on renewable energy accommodation capacity mainly embodies the minimum technical output of conventional units in Fig. 1. Proportion of thermal power and heating units in "three north" area of China is large, while proportion of power sources that can be flexibly regulated, such as pumping, storage and gas, is $4 \%$, and that in northeast area is $1.5 \%$. 


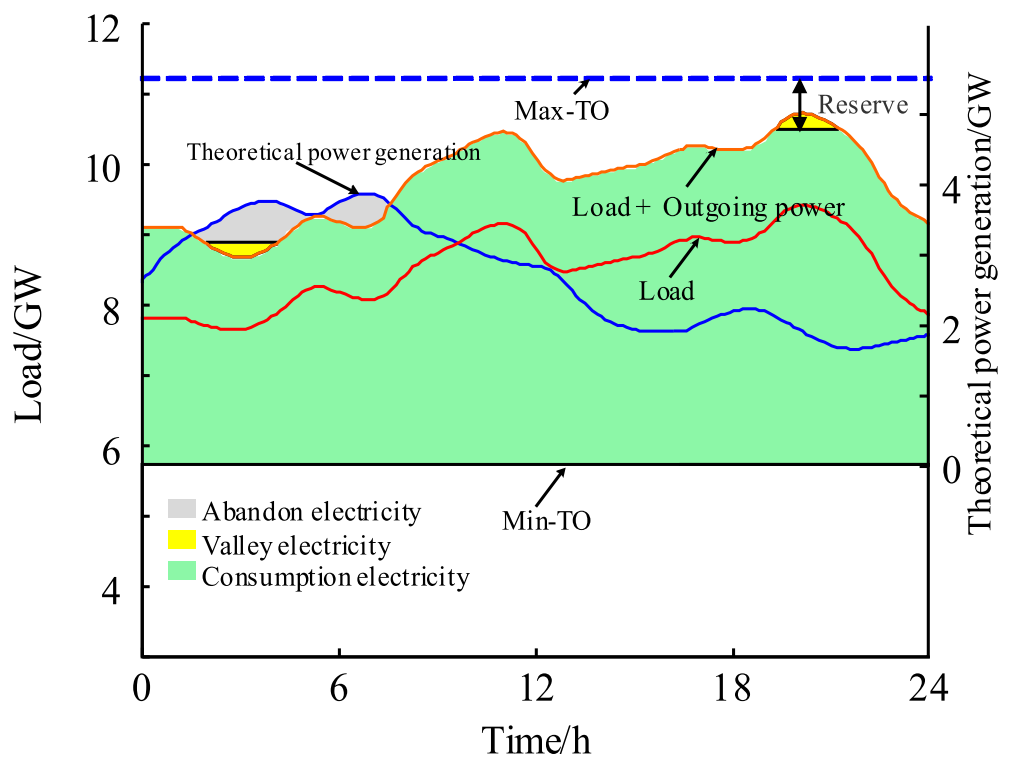

Fig. 1 Schematic diagram of renewable energy accommodation capacity calculation

Because heating unit produces electric energy while meeting the demand of heat load, in order to ensure heat supply in winter heating season, heating unit does not participate in deep peak shaving, and peak shaving capacity decreases greatly generally to $20 \%$.

Self-owned power plant is also an important factor affecting renewable energy accommodation. Owing to relatively fixed load, self-owned power plant seldom participates in system peak shaving, and public power plant and renewable energy plant are forced to participate in peak shaving. At present, installed capacity of self-owned power plants in "three north" area accounts for $13 \%$ of installed capacity of thermal power plants, and there are 6 provinces or autonomous regions where installed capacity of self-owned power plants accounts for more than $10 \%$ of total installed capacity of thermal power. It is very disadvantageous to reduce grid minimum technical output and enhance renewable energy accommodation capacity.

\subsection{Grid side analysis}

The influence of grid side on renewable energy accommodation capacity is mainly reflected in the outgoing power of tie-line in Fig. 1. This is also the main research direction of this paper, that is, how to make full use of existing inter-provincial tie-line transmission channel capacity to promote renewable energy consumption. China's renewable energy resources and loads are conversely distributed. Renewable energy resource-rich areas usually have limited load levels. Large-scale renewable energy installation and grid-connected put forward higher requirements for power system delivery capacity. Construction of renewable energy inter-provincial and inter-regional delivery channels is the key factor affecting renewable energy consumption. The capacity of inter-provincial tie-lines with renewable energy transmission is about 20,000 MW, and the scale is quite large. However, utilization level of existing inter-provincial tie-line transmission capacity is limited, and it is difficult to absorb renewable energy in a wider range. With limited scale of tie-line transmission channels, improving their utilization level has become an urgent practical problem.

\subsection{Load side analysis}

The influence of load side on renewable energy accommodation capacity is mainly reflected in the load curve of Fig. 1. China's renewable energy installed is concentrated in "three north" region, which accounts for $36 \%$ of national total load, but concentrates $75 \%$ of the country's renewable energy installations. The ratio of renewable energy installed to local load in eastern Mongolia and Gansu is $170 \%$ and $140 \%$ respectively, which has surpassed $93 \%, 78 \%$ and $63 \%$ of developed countries such as Denmark, Spain and Portugal. Such incongruous scale of renewable energy installed to load scale has led to a more serious problem of wind abandonment and PV abandonment in "three north" region. Therefore, expanding load scale has become an effective means to enhance renewable energy accommodation capacity, especially in the areas with high proportion of renewable energy.

\section{Capacity calculation model}

\subsection{Basis of capacity calculation}

This paper presents a renewable energy accommodation capacity calculation model considering utilization level of inter-provincial and inter-regional tie-lines, which is based on renewable energy time series production simulation [20]. Under given load conditions, operation of 
each generator set is simulated. The load and unit output of power grid are regarded as time series varying with time, and renewable energy output is simulated. Then some operation indices of power grid within a certain period can be calculated. This kind of production simulation process needs to consider various constraints such as load balance, unit climbing, power flow limit and so on. Generally, the objective function is to maximize accommodation capacity of renewable energy or to optimize the economic performance of grid, and optimal simulation results can be obtained, which conform to actual power system operation. Time series production simulation plays an important role in operation and decision-making of power generation system. Short-term production simulation usually ranges from a few hours to a week, which can provide a reasonable generation plan for dispatching department. Long-term production simulation time ranges several months or years, which can be used as reference basis of power grid planning and construction.

\subsection{Renewable energy accommodation capacity calculation model considering utilization level of inter- provincial and inter-regional tie-lines}

As mentioned above, a key measure to enhance accommodation capacity of renewable energy at this stage, is to make full use of transmission capacity of inter-provincial and inter-regional tie-lines. This paper considers constraint of increasing the utilization level of inter-provincial and interregional tie-lines in time series production simulation model, establishes accommodation capacity calculation model, and focuses on impact of different tie-lines utilization level on renewable energy accommodation. Based on ensuring safe and stable operation of power system and continuous power supply, multi-system time series production simulation with network constraints and renewable energy output constraints is adopted to calculate renewable energy accommodation capacity of each region.

The optimization objective of renewable energy time series production simulation model is to maximize renewable energy accommodation capacity in the whole system during calculation cycle, so the objective function in optimization cycle is as follows:

$$
F=\max \sum_{n=1}^{N}\left[P_{w}(t, n)+P_{p v}(t, n)\right](1 \leq t \leq T)
$$

Where: $N$ is total number of provincial power grids contained in the regional power grid, $n$ is a provincial power grid, $T$ is total length of calculation time, $t$ is simulation time step, $P_{w}(t, n)$ is wind power output of provincial power grid $n$ in time $t$, and $P_{p \nu}(t, n)$ is PV power output of provincial power grid $n$ in time $t$.
(1) Regional load balance constraint.

$$
\begin{aligned}
& \sum_{j=1}^{J} P_{j}(t, n) \cdot S_{j}(t, n)+P_{w}(t, n)+P_{p v}(t, n) \\
& \quad+L_{i}(t) \\
& \quad=P_{l}(t, n)
\end{aligned}
$$

Where: $\sum_{j=1}^{J} P_{j}(t, n) \cdot S_{j}(t, n)$ is total power of all conventional units in provincial power grid $n$ during the period $t, L_{i}(t)$ is transmission power of inter-provincial tie-line $i$ during the period $t$, which is positive with receiving and negative with sending.

(2) Transmission capacity constraints of interprovincial and inter-regional tie-lines

$$
-L_{i, \max } \leq L_{i}(t) \leq L_{i, \max }
$$

Where: $L_{i, \max }$ and $-L_{i, \max }$ are the upper and lower limits of transmission capacity of tie-line $i$, respectively, which are generally determined by system stability level.

(3) Unit output constraints

$$
\begin{aligned}
& 0 \leq \Delta P_{j}(t, n) \leq\left[P_{j, \max }(t, n)-P_{j, \min }(t, n)\right] \\
& \quad \cdot S_{j}(t, n) \\
& P_{j}(t, n)=P_{j, \min }(t, n) \cdot S_{j}(t, n)+\Delta P_{j}(t, n)
\end{aligned}
$$

Where: $\Delta P_{j}(t, n)$ is optimization power constraint of conventional units.

(4) Optimization of power ramp rate constraint for generating units

$$
\begin{aligned}
& P_{j}(t+1, n)-P_{j}(t, n) \leq \Delta P_{j, u p}(n) \\
& P_{j}(t, n)-P_{j}(t+1, n) \leq \Delta P_{j, \text { down }}(n)
\end{aligned}
$$

Where: $\Delta P_{j, \text { up }}$ and $\Delta P_{j, \text { down }}$ are upper and lower slope rate of unit $j$ respectively.

(5) Renewable energy output constraints

$$
0 \leq P_{w}(t, n) \leq P_{w}^{*}(t, n)
$$




$$
0 \leq P_{p v}(t, n) \leq P_{p v}^{*}(t, n)
$$

Where: $P_{w}{ }^{\prime \prime}(t, n)$ refers to wind power time series output when the capacity of time $t$ is fixed, and $P_{p v}{ }^{\prime \prime}(t, n)$ refers to PV time series output when the capacity of time $t$ is fixed.

(6) At present, inter-regional transmission channel is mainly DC tie-lines, and inter-provincial transmission channel is mainly AC tie-lines in regional power grid. The utilization level and operation characteristics of AC/DC tie-lines should be fully considered in the process of sequential production simulation. In combination with actual operation situation of inter-provincial and inter-regional tielines in China. There are three main types of tielines constraints: transmission capacity constraints [21] (in Formula (3)), electricity scale constraints $[22,23]$ and operation power curve constraints.

1) electricity scale constraint of inter-provincial and inter-regional tie-lines:

$$
(1-D) \cdot Q_{L_{i}} \leq \int_{t=1}^{T} L_{i}(t) \cdot \Delta t \leq(1+D) \cdot Q_{L_{i}}
$$

Where: $Q_{L i}$ is the electricity upper limit of tie-line $L_{i}$, that is, annual transmission electricity plan, $D$ is the assessment deviation coefficient of inter-provincial tie-line electricity, usually taking $5 \%$. With further promotion of power market, deviation assessment of tie-line electricity will become normal.

2) Power curve constraint of inter-provincial and inter-regional tie-lines:

$$
\left\{\begin{array}{c}
P_{i, \text { shoulder }}=k_{1} \cdot P_{i, \text { peak }} \\
P_{i, \text { valley }}=k_{2} \cdot P_{i, \text { peak }} \\
T_{i, \text { valley }} \in\left(0, t_{s 1}\right) \vee\left(t_{s 1}, 24\right) \\
T_{i, \text { shoulder }} \in\left(t_{s 2}, t_{s 3}\right)
\end{array}\right.
$$

Where: $P_{i, \text { speak }}, P_{i, \text { shoulder }}$ and $P_{i, \text { valley }}$ are peak load, waist load and base load of tie-lines curve, $k_{1}$ and $k_{2}$ are the corresponding proportional coefficients, $T_{i \text {,shoulder }}$ and $T_{i, v a l l e y}$ are the duration of waist load and base load of tie-lines curve, $t_{s 1}, t_{s 2}$ and $t_{s 3}$ are the time dividing points of base load, peak load and waist load of tie-lines curve, respectively. Normally, $24 \mathrm{~h}$ in one day is divided two parts of basic load, two parts of peak load and one part of waist load.

Based on time series production simulation of renewable energy, this paper introduces the factor of inter-provincial tie-lines utilization lever, and quantitatively analyzes the impact of inter-provincial tie-lines utilization on the increase of renewable energy accommodation capacity. The utilization level of inter-provincial tie-lines mainly depends on selection of tie-lines constraints. The accommodation capacity of tie-lines constrained by operation power curve is relatively limited, and many DC inter-provincial tie-lines are constrained by this constraint, and their utilization level is low. Accommodation capacity is slightly better when constrained by electricity scale, and the reason is that their curve of some periods can be determined by renewable energy sources' output. Renewable energy accommodation capacity is the largest when tie-lines is only constrained by transmission capacity, and tie-lines flow can be flexibly adjusted according to system's needs, which is equivalent to improving system's comprehensive peak shaving capacity. The calculation flow chart of renewable energy accommodation capacity considering utilization level of inter-provincial tie-lines is shown in Fig. 2.

\subsection{Model solution}

The calculation model of renewable energy accommodation capacity considering utilization level of inter-provincial tie-lines is a mixed integer programming model. It contains all kinds of constraints of units. This paper uses branch and bound method to solve this problem and optimize operation mode of the whole calculation cycle. This method can be used to solve complex mixed integer programming problem with high efficiency under the condition of guaranteeing accuracy and robustness of optimal solution. It can calculate renewable energy accommodation capacity considering tie-line utilization level more easily. The advantage of this method is that it can find the minimum bound point by searching, and the optimal solution can be obtained quickly. The computation of bounds and corresponding matrices generally takes much more memory space.

\section{Engineering example verification}

In order to verify the validity of renewable energy accommodation capacity calculation model in this paper, it is applied to the calculation of renewable energy accommodation capacity in the "three north" region in 2020, mainly verifying the influence of inter-provincial tie-lines utilization level on renewable energy accommodation capacity.

\subsection{Situation of tie-lines in "three north" area of China}

Northwest China: It is divided into five zones. Because of the serious problem of wind abandonment and PV abandonment in Gansu and Xinjiang province at present, it is necessary to study important provincial sections in the two zones in detail. The zones are connected with out-of-district systems through inter-provincial transmission lines, mainly UHVDC tie-lines. Northwest 


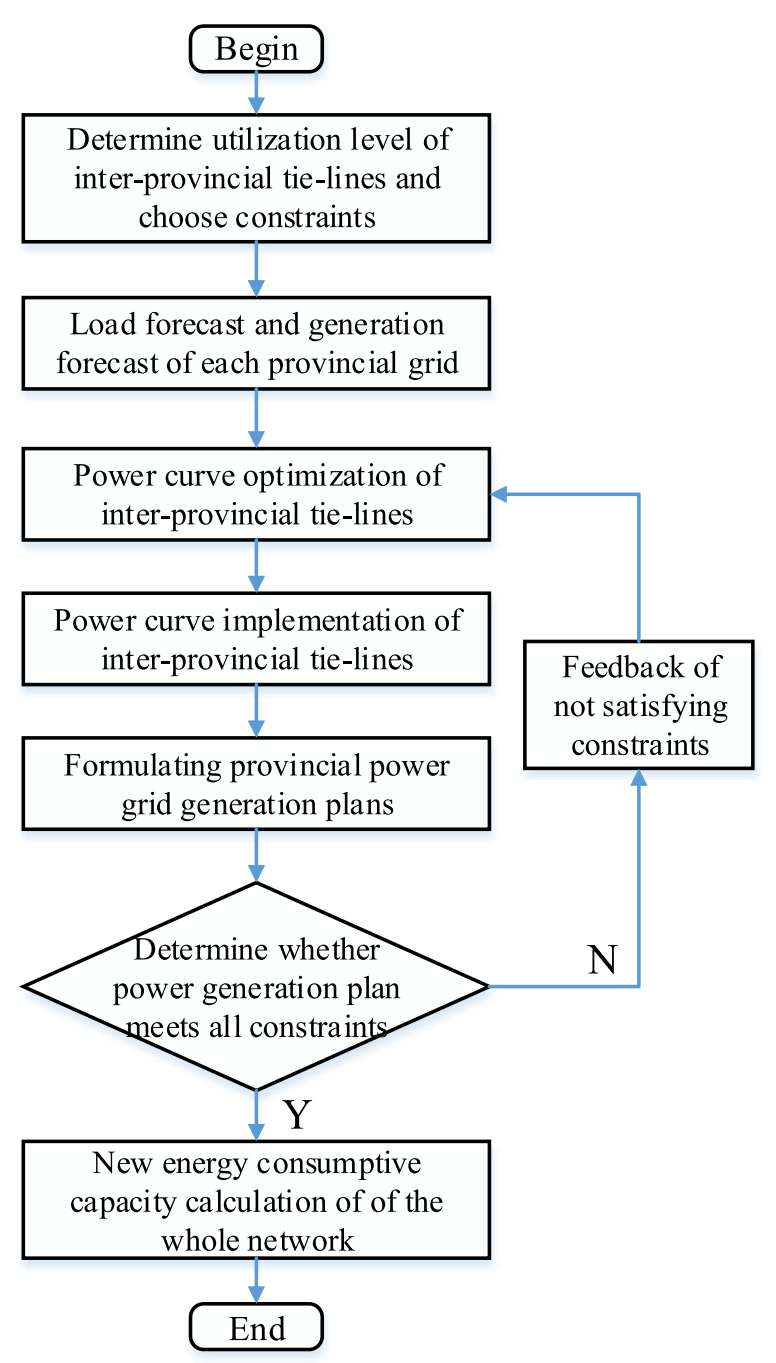

Fig. 2 Flow chart of renewable energy accommodation capacity calculation

China Grid is connected with North China, East China, Central China and Tibet Grids by HVDC or UHVDC transmission channels, as shown in Fig. 3.

Northeast China: It is divided into four zones, mainly with provincial administrative regions as independent zones. Each zone is connected by inter-provincial tie-lines. Northeast China Grid is connected to North China Grid through Gaoling back-to-back DC, Suizhong power plant renovation Project and Zahrut-Qingzhou UHVDC Tie-line, as shown in Fig. 4.

North China: It is divided into six zones, mainly with provincial administrative regions as independent zones. Hebei is divided into two zones, North Hebei and South Hebei. Each zone is connected by inter-provincial tie-lines, and is connected with the outside of the zone through cross-regional AC and DC liaison lines. The exchange capacity of tie-lines is affected by security and stability capacity. North China Grid is connected with East China,
Central China, Northwest China and West Mongolia Grids by AC or DC transmission channels, as shown in Fig. 5 .

\subsection{Boundary conditions}

Considering utilization level of inter-provincial and inter-regional tie-lines, the calculation of renewable energy accommodation capacity in "three north" region of China needs to consider various boundary conditions of power system, including system reserve settings, maximum and minimum technical output of conventional thermal power units, system load level and so on, as shown in Table 1.

It should be noted that in order to facilitate the calculation of practical engineering cases, computational boundary conditions adopted in this paper has been simplified that affecting renewable energy accommodation.

\subsection{Scenario setting}

In order to compare and analyze the validity of calculation model, four different schemes are set up to verify the validity of model. As shown in Table 2, main factors include power supply, power grid and load. Among them, power supply side mainly considers minimum start-up constraints of thermal power relatively fixed, and power grid side mainly considers utilization level of transmission channels within and across provinces, such as stability constraint, power constraint and curve constraint, and load side is relatively fixed. In order to better verify the impact of utilization level of inter-provincial tie-lines on renewable energy accommodation capacity, load side and power side constraints are relatively fixed, while grid side mainly considers system stability constraints and power constraints of inter-provincial and inter-regional channels. The utilization level of inter-provincial tie-lines rises in turn in Schemes 14 increases. The main data in this paper come from China's "13th 5-Year" electric power planning [24].

In particular, this paper focuses on the impact of cross-provincial tie-lines on the renewable energy accommodation capacity, and stability constraint is one of the important factors. This constraint is considered in the analysis of the calculation model. That is to say, the power limit of tie-lines is set in the process of simulation analysis, which is generally larger than the power limit under the power plan constraints. It is determined by the physical parameters of power system itself. However, the specific reasons are not discussed in detail in this paper.

\subsection{Example results}

\subsubsection{Example results of Northwest China}

According to calculation, renewable energy accommodation capacity under the 4 calculation schemes in Northwest China in 2020 is shown in Fig. 6.

Without considering inter-provincial power exchange and inter-regional transmission channels, local wind and 


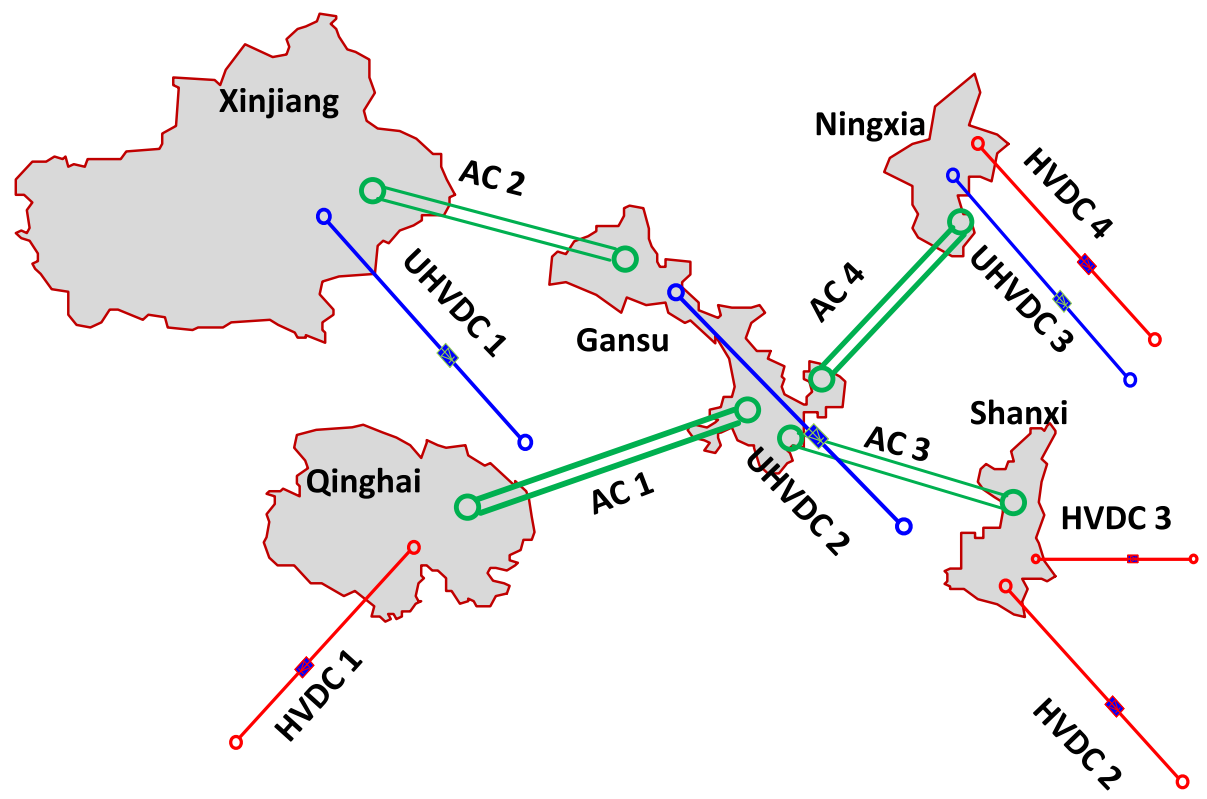

Fig. 3 Tie-lines map of Northwest region of China

PV power accommodation capacity in Northwest China are 12,500 and 10,000 MW, respectively.

After considering inter-provincial exchange and inter-regional transmission, installed capacity of wind and PV power in Northwest China can be increased to 23,000 and $18,600 \mathrm{MW}$ in turn. Based on clear inter-regional outgoing channel and reasonable inter-provincial exchange of electricity, Northwest China will be able to accept 40,900 MW wind power and 36,800 MW PV in 2020. On this basis, after further increasing inter-provincial exchange of electricity, renewable energy accommodation capacity can be further increased by $15.2 \%$.

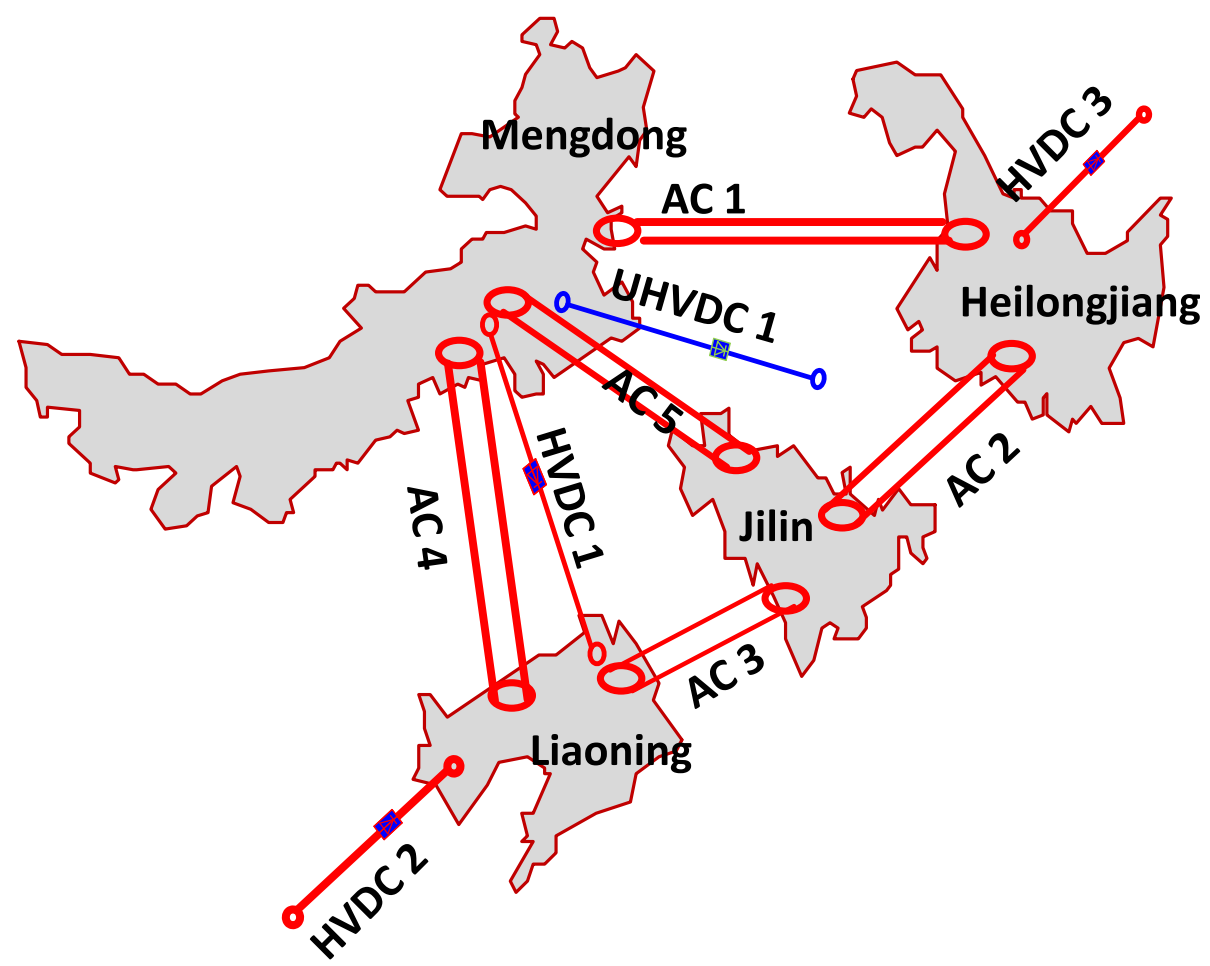

Fig. 4 Tie-lines map of Northeast region of China 


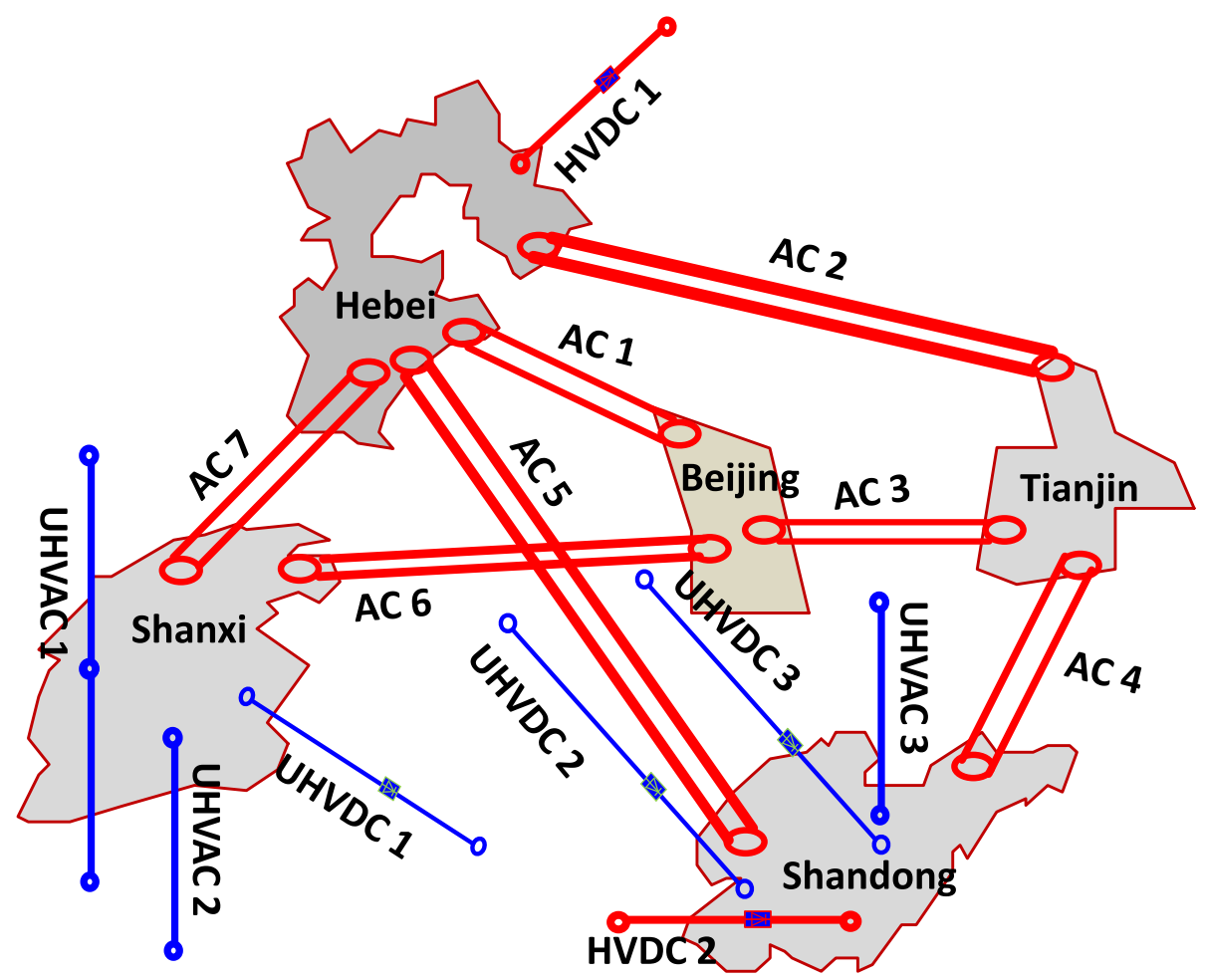

Fig. 5 Tie-lines map of North region of China

Table 1 Boundary condition of renewable energy accommodation capacity in "Three North" region of China in 2020

Boundary conditions
1. System reserve capacity
2. Units starting mode
3. The maximum and minimum technica
output selection of thermal power units

4. Load data

5. Constraint conditions with hydro-power participation in balance

\section{Annual renewable energy utilization hours with no obstruction}

7. Normalized sequence of renewable energy

8. Treatment principle of tie-lines

Basic principles

Max $\{5 \%$ of the maximum load, the maximum capacity of a single unit (or one polar of DC system)\}. Participation in power balance of wind and PV power in accordance with the forecast value minus the installed capacity of $20 \%$.

Units start and stop with the minimum cycle once a week.

Arrangement according to actual operation of units, while that cannot get the actual situation according to following arrangements:

(1) The maximum technical output under the gas condenser condition:According to unit rated capacity.

(2) The minimum technical output under the gas condenser condition:Calculation as $60 \%$ of the rated capacity of over $200 \mathrm{MW}$, and heating units are considered in the early stage, middle stage and final stage of heating period.

Load curve of one year is based on historical load curve, considering a certain rate of load forecast growth, as the based data of renewable energy accommodation ability assessment.

The maximum and minimum technical output of hydro-power is determined according to the actual operation requirements, and the utilization hours per year in accordance with the average level of nearly 3 years.

Estimates in accordance with average resources over the past 3 years are calculated, simultaneously taking into account floating 10\% for sensitivity analysis.

Renewable energy output is returned to original condition or shape on the basis of obstruction, and then formed a normalized sequence.

Tie-lines are treated according to their historical operation reality. 
Table $\mathbf{2}$ List of case setting

\begin{tabular}{|c|c|c|c|c|c|}
\hline \multirow[t]{2}{*}{ Scheme } & \multirow{2}{*}{$\begin{array}{l}\text { Power side } \\
\text { Minimum technical } \\
\text { output }\end{array}$} & \multicolumn{3}{|l|}{ Grid side } & \multirow{2}{*}{$\begin{array}{l}\text { load side } \\
\text { Total social electricity } \\
\text { accommodation (TWh }\end{array}$} \\
\hline & & Provincial channel & Inter-provincial channel & Inter-regional channel & \\
\hline 1 & $\sqrt{ }$ & Curve constraint & Curve constraint & Curve constraint & 7100 \\
\hline 2 & $\sqrt{ }$ & Stability constraint & Electricity constraint & Curve constraint & 7100 \\
\hline 3 & $\sqrt{ }$ & Stability constraint & Stability constraint & Electricity constraint & 7100 \\
\hline 4 & $\sqrt{ }$ & Stability constraint & Stability constraint & Stability constraint & 7100 \\
\hline
\end{tabular}

\subsubsection{Example results of Northeast China}

It is estimated that renewable energy capacity in the northeast of China under 4 calculation schemes in 2020 is shown in Fig. 7.

Without considering inter-provincial power exchange and inter-regional transmission channels, local wind and PV power accommodation capacity in Northeast China is 10,400 and $1300 \mathrm{MW}$, respectively.

After considering inter-provincial exchange and inter-regional transmission, installed capacity of renewable energy in Northeast China can be increased by 14,250 and $2600 \mathrm{MW}$ in turn. Based on clear inter-regional outbound channel and reasonable inter-provincial exchange electricity measurement, renewable energy accommodation capacity of Northeast China in 2020 will be $21,700 \mathrm{MW}$ wind power and $3450 \mathrm{MW}$ PV power. On this basis, renewable energy accommodation capacity will be greatly increased after further increase of electricity exchange between provinces.

\subsubsection{Example results of North China}

It is estimated that renewable energy accommodation capacity under 4 calculation schemes in North China in 2020 is shown in Fig. 8.

Without considering inter-provincial power exchange and inter-regional transmission channels, accommodation capacity of wind and PV power in North China is 8000 and $7000 \mathrm{MW}$ respectively.

After considering inter-provincial power exchange and inter-regional transmission, installed renewable energy accommodation capacity in North China can be increased to 19,300 and 17,500 MW in turn. Based on clear inter-regional outbound channel and reasonable inter-provincial exchange of electricity, renewable energy accommodation capacity of North China in 2020 will be $26,000 \mathrm{MW}$ wind power and 22,500 MW PV power. On this basis, further increasing electricity exchange between provinces can further increase renewable energy accommodation capacity by $8.6 \%$.

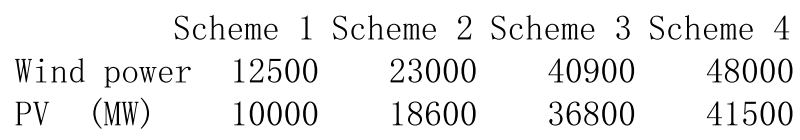

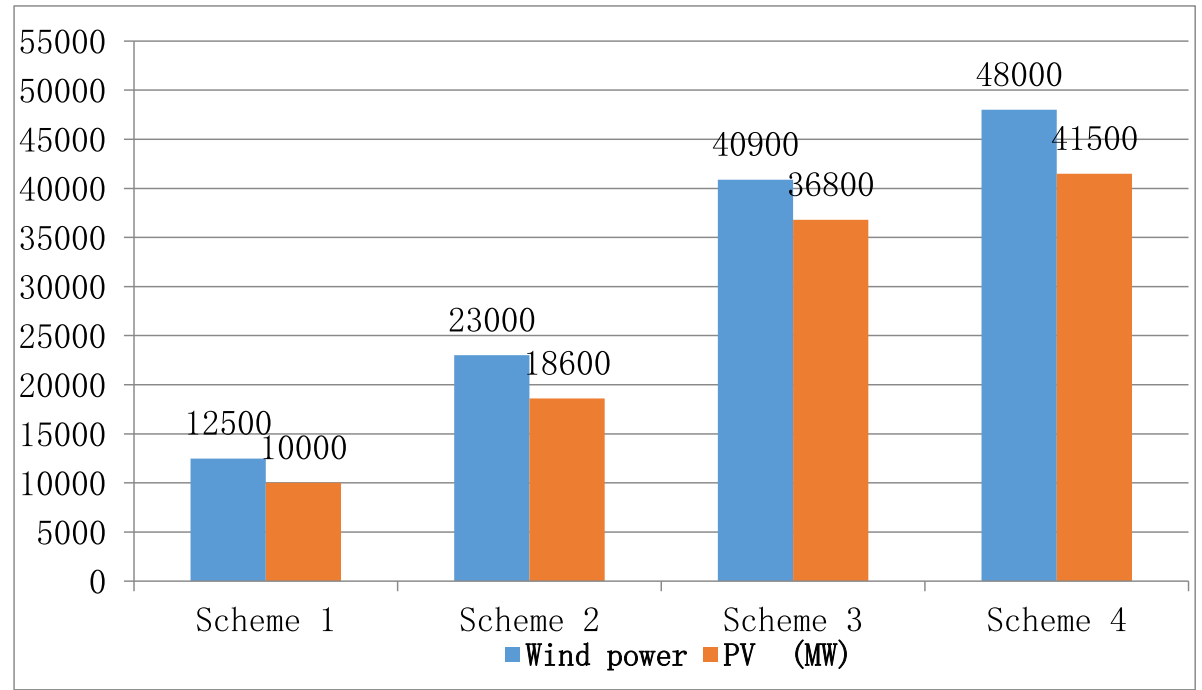

Fig. 6 Wind power and PV power accommodation capacity of Northwest region 
Scheme 1 Scheme 2 Scheme 3 Scheme 4

$\begin{array}{lrrrr}\text { Wind power } & 10400 & 14250 & 21700 & 31500 \\ \text { PV (MW) } & 1300 & 2600 & 3450 & 6900\end{array}$

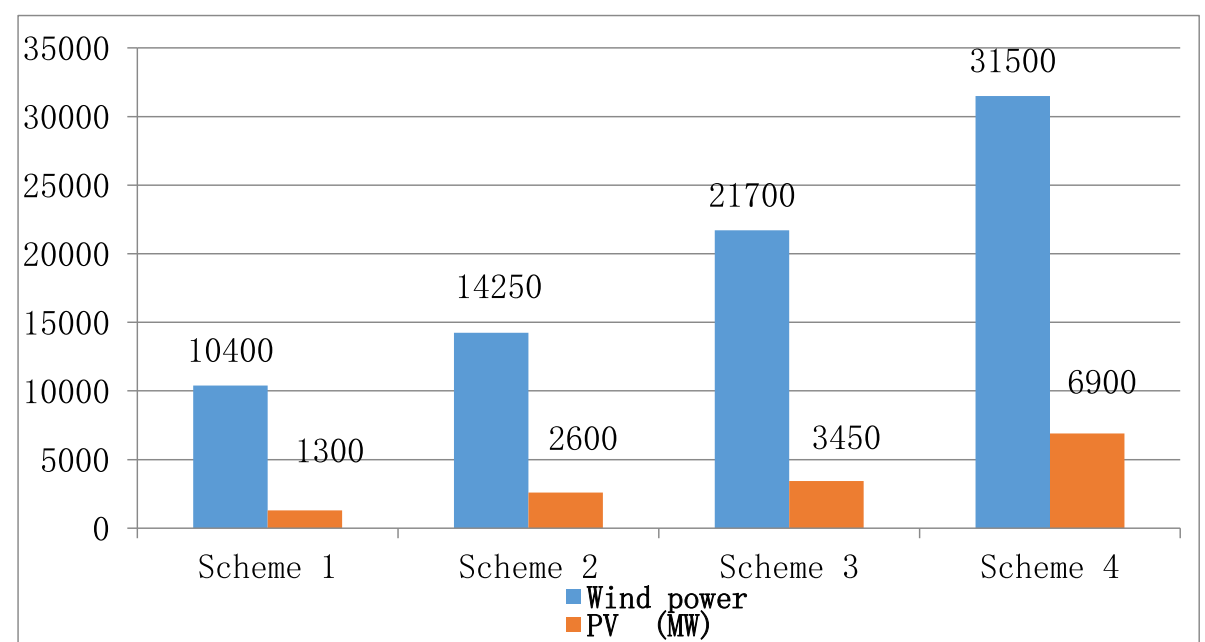

Fig. 7 Wind power and PV power accommodation capacity of Northeast region

\subsection{Comprehensive analysis}

The results show that of renewable energy accommodation capacity in Northwest, Northeast and North China has been greatly increased, and renewable energy accommodation capacity has been greatly increased after fully considering exchange capacity of inter-provincial and inter-regional transmission passages and enhancing their utilization level, including curve constraint, electricity constraint and stability constraint. Maximum accommodation capacity of the three regions are $89,500,38,400$ and 52,700 MW, respectively. It can be seen that utilization level of inter-provincial and inter-regional tie-lines transmission capacity can greatly improve renewable energy accommodation level.

Scheme 1 does not consider use of inter-provincial tie-lines transmission channels, that is, the main way to absorb renewable energy in the province, and all kinds of transmission channels are constrained by fixed curves. The results show that level of renewable energy accommodation in Northwest, Northeast and North China is very low, far less than the installed scale of each region.

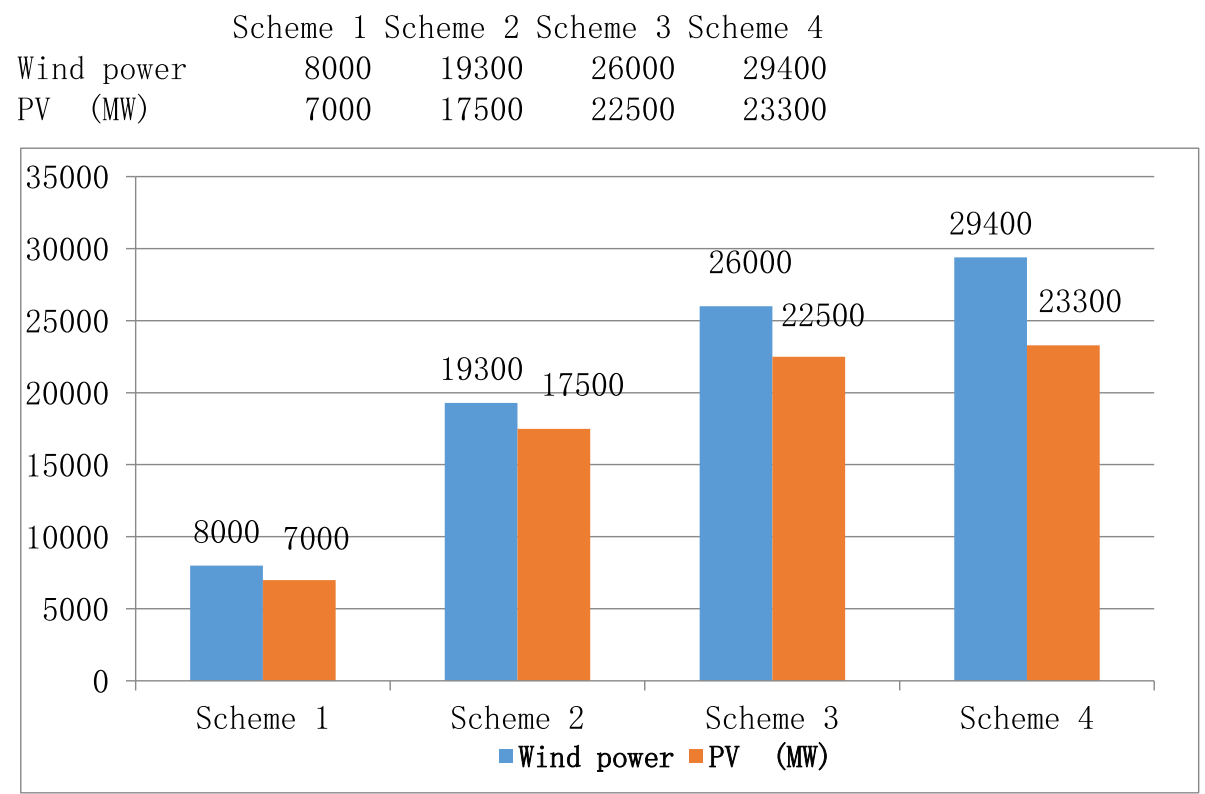

Fig. 8 Wind power and PV power accommodation capacity of North region 
On the basis of Scheme 1, Scheme 2 adds the utilization of provincial transmission channels and inter-provincial channels in regional power grid. Provincial channels are only constrained by stability constraint, and inter-provincial channels within the region are constrained by power accommodation, thus expanding scope of renewable energy accommodation and constraining inter-provincial tie-lines transmission channels within the region. It can be seen that accommodation capacity of renewable energy in Northwest, Northeast and North China has increased by $85 \%, 44 \%$ and $145 \%$ respectively.

On the basis of Scheme 2, Scheme 3 enhances the utilization of inter-provincial tie-lines transmission channels. The inter-provincial channels in the region are only constrained by stability, and inter-regional channels are constrained by power accommodation, thus further expanding scope of renewable energy accommodation. The calculation results show that accommodation capacity of Northwest, Northeast and North China has increased by 87\%, 49\% and 32\% respectively compared with Scheme 2.

On the basis of Scheme 3, Scheme 4 further liberalizes constraints of inter-regional transmission channels, subject only to stability constraints, that is, all inter-provincial and inter-regional tie-lines are flexibly adjusted according to demand for renewable energy accommodation, and further expands space for outward transmission. From example results, accommodation capacity of Northwest, Northeast and North China increase by $15.2 \%, 52.6 \%$, $8.6 \%$ respectively than Scheme 3.

Generally speaking, the promotion of utilization level of provincial and inter-provincial tie-lines in the "three north" region plays a more obvious role in expanding capacity of renewable energy accommodation, while the role of inter-regional tie-lines is relatively limited. In different regions, opening inter-provincial tie-lines in northwest region has obvious effect, opening inter-regional tie-lines in northeast region has obvious effect, and opening relevant transmission channels in north region has obvious effect.

\section{Conclusions}

Renewable energy accommodation capacity is constrained by system power source characteristics, structure of large power grid, load distribution and so on. This paper mainly studies influence of the utilization level of inter-provincial tie-lines on renewable energy accommodation capacity. Based on time series production simulation model of renewable energy, a renewable energy accommodation capacity calculation model considering the utilization level of inter-provincial tie-lines is proposed. The renewable energy accommodation capacity of "three north" region in 2020 is calculated by the proposed model. Based on the differences of curve constraints, power constraints and stability constraints of provincial, inter-provincial and inter-regional corridors, four different schemes are designed for comparative analysis. Through the case study, it is found that making full use of inter-provincial and inter-regional tie-lines can effectively enhance renewable energy accommodation capacity in Northwest, Northeast and North China, and the improvement of utilization level of inter-provincial and inter-regional tie-lines in Northwest and Northeast has relatively obvious effect on the promotion of the renewable energy accommodation capacity. The study in this paper is the basis of renewable energy accommodation research, which can provide a strong support for grid planning and dispatching control.

\section{Acknowledgements}

Not applicable.

\section{Funding}

This work is supported by project of the National Key Research and Development Program Foundation of China (2016YFB0900100).

Availability of data and materials

Please contact author for data requests.

\section{Authors' contributions}

$G L$ conceived and designed the study. $G L$ and $M Z$ performed the engineering example verification. $G L$ and $G L$ wrote the paper. $G L, G L$ and $\mathrm{MZ}$ reviewed and edited the manuscript. All authors read and approved the manuscript.

\section{Competing interests}

The authors declare that they have no competing interests.

Received: 11 September 2018 Accepted: 15 January 2019

Published online: 30 January 2019

\section{References}

1. Yinbiao, S., Zhigang, Z., Jianbo, G., et al. (2017). Study on key factors and solution of renewable energy accommodation [J]. Proceedings of the CSEE, $37(1), 1-8$.

2. Guoping, C., Mingjie, L., Tao, X., et al. (2017). Study on technical bottleneck of new energy development [J]. Proceedings of the CSEE, 37(1), 20-26.

3. Doherty, R., \& O'Malley, M. (2005). A new approach to quantify reserve demand in systems with significant installed wind capacity [J]. IEEE Transactions on Power Systems, 20(2), 587-595.

4. Li, J., Wang, S. Ye, L., et al. (2018). A coordinated dispatch method with pumped-storage and battery-storage for compensating the variation of wind power. Protection and Control of Modern Power Systems, 3(3), 21-34.

5. Li, Z., Ye, L., Zhao, Y., et al. (2016). Short-term wind power prediction based on extreme learning machine with error correction. Protection and Control of Modern Power Systems, 1(1), 9-16.

6. Ummels, B. C., Gibescu, M., Pelgrum, E., et al. (2007). Impacts of wind power on thermal generation unit commitment and dispatch []]. IEEE Transactions on Energy Conversion, 22(1), 44-51.

7. Cun, D., Mingjie, L., Gaofeng, F., et al. (2015). Research and application of renewable energy accommodation capability evaluation based on time series production simulation [J]. Electric Power, 48(12), 166-172.

8. Yang, C., Peng, L., Yue, Y., et al. (2014). Analysis on accommodating capability of renewable energy and assessment on low carbon benefits based on time sequence simulation [J]. Automation of Electric Power Systems, 38(17), 60-66.

9. Wang, J. (2017). Wind power accommodation capacity evaluation model based on complex network [J]. Electric Power, 50(1), 136-139.

10. Pengbo, L., Rongjun, L., Chunxiao, M., et al. (2015). Wind power accommodation capacity evaluation model based on complex network [J]. Advanced Technology of Electrical Engineering and Energy, 34(8), 25-31.

11. Jianfang, T., Yashan, M., Qiaozhu, Z., et al. (2015). Security constrained unit commitment with wind power based on evaluation of wind power penetration capacity [J]. Power System Technology, 39(9), 2398-2403. 
12. Hongzhong, L., Zhenbang, L., Jiaming, Z., et al. (2017). Dynamic evaluation on day-ahead wind power accommodation with economic consideration [J]. Power System Technology, 41(4), 1261-1268.

13. Chongqing, K., Wenzhao, J., Qianyao, X., et al. (2013). Capability evaluation of wind power accommodation considering security constraints of power grid in real-time dispatch [J]. Proceedings of the CSEE, 33(16), 23-29.

14. Jianbo, H., Zhijian, H., Menglin, Z., et al. (2014). Coordinated optimal dispatching of wind-thermal-hydro power system considering constraint of real-time expected demand not supplied [J]. Power System Technology, 38(7), 1898-1906.

15. Chaoqun, W., Hua, W., \& Siyuan, W. (2017). Stochastic-security-constrained unit commitment considering uncertainty of wind power [J]. Power System Technology, 41(5), 1419-1427.

16. Xiaolin, G., \& Lizi, Z. (2014). Wind-hydro-thermal stochastic unit commitment problem considering the peak regulation constraints [J]. Transactions Of China Electrotechnical Society, 29(10), 222-230.

17. Dongxiao, N., Jianfeng, L., Linjun, W., et al. (2016). Study on technical factors analysis and overall evaluation method regarding wind power integration in trans-provincial power grid [J]. Power System Technology, 40(4), 1087-1093.

18. Rongfu, S., Tao, Z., \& Ji, L. (2011). Evaluation and application of wind power integration capacity in power grid [J]. Automation of Electric Power Systems, 35(4), 70-76.

19. Che, G., Dongxiao, N., Ming, M., et al. (2017). Accommodating capability analysis and comprehensive assessment method of large-scale new energy areas interconnected []]. Electric Power, 50(7), 56-63.

20. Ming, D., Yujuan, L., \& Hao, P. (2016). Probabilistic production simulation considering time sequence characteristics of load and new energy []]. Proceedings of the CSEE, 36(23), 6305-6374.

21. Haiwang, Z., Qing, X., Maosheng, D., et al. (2015). A new model of HVDC tieline operation optimization for maximizing renewable energy accommodation [J]. Automation of Electric Power Systems, 39(3), 36-42.

22. Fan, X., Qia, D., Hongwei, H., et al. (2017). Power optimization model and analysis of HVDC tie-line for promoting integration of inter-regional renewable energy accommodation [J]. Automation of Electric Power Systems, 41(18), 152-159.

23. Zheng, D., Eseye, A. T., Zhang, J., et al. (2017). Short-term wind power forecasting using a double-stage hierarchical ANFIS approach for energy management in micro-grids [J]. Protection and Control of Modern Power Systems, 2(2), 136-145.

24. National Development and Reform Commission, \& National Energy Administration. (2016). Thirteenth Five-Year Plan for Electric Power Development (2016-2020) [N]. China Energy Daily, (1), 1-8.

\section{Submit your manuscript to a SpringerOpen ${ }^{\circ}$ journal and benefit from:}

- Convenient online submission

- Rigorous peer review

- Open access: articles freely available online

High visibility within the field

- Retaining the copyright to your article

Submit your next manuscript at $\boldsymbol{\nabla}$ springeropen.com 